\title{
The Inappropriate or Negligent Medical Treatment in Albanian Criminal Legislation
}

\author{
Rovena Kastrati \\ PhD candidate, Faculty of Law, University of Tirana, Albania
}

rovena_kastrati@hotmail.com

\begin{abstract}
We are all testimonials for the failure or on-go of the medical treatment and of all the medicine in general, even though we are in a century of considerable scientific evolution. The inevitable involvement of doctors in the everyday life of human beings, leads to the necessity that people must have legal protection from medical offense. The most important right, the right to live, requires that doctors and medical staff have to protect and respect the life of the patients, but the careless treatment and medical neglect in many cases has lead to permanent injuries of human health or lost of life. The cases that have been submitted in the court have been suspended, discontinued or the doctors have been declared innocent, because of impossibility to prove that the pretended medical offense has lead to severe impairment of health or even worse to death. According to this situation hundreds of cases have not been reported, and as a result the repetition of these medical offenses and lack of awareness from the medical staff, regarding their professional liability. Taking into account that the evidence of the Albanian criminal legislation provides de jure protection for its patients, in reality this protection de facto does not operate properly, i have introduced my project which is divided into 3 parts/sections. In the first part I have mentioned the evolution of medical outlook, from the antiquity to modern times, the international devices that protect and guarantee the freedoms and right of the patients and the modifications in the relationships between doctors and patients. Further, in the second part I have been focusing on "negligent medical treatment" in our legislation, and in the experience of some more European countries and more. In the third and last part I have submitted the whole economical, social factors that do affect the actualization of this offense otherwise known as "medical neglect" and the possible preventive provisions of this offense.
\end{abstract}

Keywords: patient-doctor relationship, negligent, court, negligent medical treatment

\section{Introduction}

Medicine is a science developed enough that, thanks to advanced technology, have made possible a health welfare unimaginable couple of years ago. Nowadays, thanks to this medical development, humans fight most of the disease and live longer. However, we all are conscious for the other side of the medal which represents the dark side of science. Failures are those that stand alongside the accomplishments and make us think that should still much work to be done. But what are these failures and what is their origin? Are doctors irresponsible or is the science that leaves spaces for misinterpretation? "Who" and "how" will respond to this failure? In these conditions, who is the victim: patients and their families or doctors who will face criminal responsibility? Based on this situation, I introduce this paper non pretending that I have answered all questions possible but hoping that the situation change for the better.

\subsection{Evolution of medical ethics fundamentals and changes in patient-physician relations.}

Life and human health have been under special care by the entire society since the earliest times. People in ancient times, having no obvious reason why the disease would naturally capture a person and not another, tried to find reasons in the supernatural. In that time magic and religion were a fundamental part of a healing practice (Pikoulis, Msaoue and Avgerinos). Deceitful individuals would use the healing process as a "gift" of their own, whose power depended on the ignorance of others. The first example of organized medicine appeared in ancient Egypt, practiced by Imhotep (2667-2648 $B C E)$, popularly known as the father of medicine. (Shehata) We can relate some data from that medicine organization with the modern practice, for example: a) Patients did not have to pay doctors for their medical care, as they were supported by community. b) Strict and strong rules were set on the experimental treatment. 
c) There was no responsibility in the event of the medical treatment failure, if all written rules were followed, etc.

Different punishments were set for those who had not been aware of these rules because they were expected to know the rules, even better than the specialists before them. In the 5th century BC, Greek philosophers were those who through logical process, observation and deduction, would doubt the strong influence of religion in medical treatment. Hippocrates, the most famous figure in medicine and Greek philosophy, established some principles and lines of medical ethics and later developed the so called "Hippocratic Oath". This is a statement that requires young doctors to solemnly swear to uphold specific ethical standards on their practice, an oath forwarded nowadays with occasional modifications (Miles).

Humans health and its care is very important, as noticed from antiquity, people with primitive tools and limited available options have always taken care of their health, same goes on even nowadays. In the patient-physician relations, for centuries, doctor's figure has been very important. Patients were afraid of their diseases and their treatment methods, as they had no knowledge, while control of the patient's health was a franchise of health professionals. Only in recent years the right of patients to be informed, to get explanations about their health conditions and to get involved in their health care began to gain ground. An increasing trend of patients who are controlling their health medical management is noted recently and this thanks to changes in social and economic reality (Coulter and Ellins).

The idea that all people have some fundamental rights has been at the center of attention of international organizations like the United Nations Organization or the World Health Organization. In its establishment in 1948 was defined: "to have the highest possible standards of health is a fundamental right for every human being regardless of race, religion, political beliefs, economic or social status ". Declaration of the World Health Organization for the Promotion of the Patients Rights in Europe, Amsterdam 1994, later on states: "Patients have the basic right to privacy, confidentiality, to accept or evaluate treatment and to be informed of medical procedures and their potential risks". This convention along with international acts, such as the United Nations Charter of (1945), the Universal Declaration of Human Rights (1948); European Convention of Human Rights in (1950), the European Social Charter (1961), International Treaty on Civil and Political Rights (1966), all establish the protection of fundamental human rights and simultaneously constitute the basis for protection of patient rights.

Lastly, the European Charter of Patients' Rights drafted on November 15, 2002, in Brussels paid full and specific attention to the patient's rights, constituting up to date and the full frame work defining the concept of patients' rights (European Economic and Social Committee).

\section{Overview of the offense "Careless Medication" in Albanian Criminal Code}

In actual Criminal Code of the Republic of Albania, the legislator has provided the special provision offenses that endanger human life and health. In the medical field these are: medical negligence, failure to provide assistance, HIV infection, organ transplant trafficking, falsifying medical documents, failure in keeping patients information confidential, illegal abortion etc. The fact that the criminal code expressly provides these specific acts is a good indication of the great importance legal and criminal defense pays on life and human health.

Nevertheless, the health system is not as secure as it should be and we want it to be. One of the most confusing offenses in the health care system is exactly "Careless Medication ". There have been too many dismissed cases as a result of the inability to prove medical alleged violation which brought severe damage of the patient's health or even death. But what does the term "Careless Medication" stand for? According to Article 96 of the Albanian Criminal Code expressly and superficially this would only apply on patient's treatment. Although this in the medical sense constitutes only the second stage of the patient's treatment does not mean that it leaves aside the first stage, the diagnosis. By using the term "medication" the legislator would not consider just the narrow sense of the word, simply the treatment, but rather an extensive medical treatment of the patient starting from the moment of diagnosis until the advent of effect of the treatment. Forensic experts play a determining role in assessing whether the acts and omissions of doctors or medical personnel have been illegal. Under the law, doctors are forced to practice their profession in accordance with rules and protocols of medical science. Their actions would be considered illegal if they would not be in accordance with the above.

From the medical science standpoint, medical treatment of the patient goes through two main stages:

1) diagnosis: the entirety of medical operations patient undertakes in the process of identifying the disease he suffers from. 
2) treatment: the entirety of the medical operations for determining the disease treatment scheme in accordance with the diagnosis and the application of this treatment.

The term "Careless Medication" in the direct sense of the word, may allow a path to a narrow interpretation, which is not the purpose of the legislature, to sum it up it will be, all the careless actions or omissions by the physician or medical personnel during patient's treatment (Meksi). With the above in mind we conclude that in the court practice, the offense "Careless Medication" should take into account and include all negligent acts or omissions of the physician or medical staff in the process of prevention, diagnosis and treatment of patients. In cases of medical errors, according to the Albanian criminal doctrine, doctors or medical staff is charged with criminal responsibility only when the error is professional and not in cases of scientific errors. A scientific error arises as a result of uncertainties in the science of medicine, as some notions that can be considered fair and appropriate nowadays, cannot be considered so in the future. Professional error is the one that matters for criminal responsibility (P.Pavli). The criteria on which the jurisprudence refers to the assessment of the existence of guilt in physician behavior, are the anticipation and avoidance, in the phases of diagnosis as well as in treatment. The physician or medical personnel are excluded from responsibility, when it's objectively impossible to predict and avoid risks. The court must also assess the doctor's professionalism, whether he is a general practitioner or a specialist. One cannot ignore the fact that the doctor is a general practitioner or a specialist, and a famous professor. For the doctor to be found guilty of the criminal offense of "Careless Medication" all the above causal link need to be proven (that there have been these illegal acts or omissions causing serious harm to health or death of the patient)

The doctor shall be criminally liable if it is proven that: 1 . There have been careless actions and omissions, inaccurate diagnosis or treatment against the rules of medicine. 2. The fault exists. 3. The death of the patient or serious damage to his health is verified. 4. If the diagnosis would have been accurate and the therapy appropriate, injury or death wouldn't come, or would be verified at a later period, or would be less damage (Lole). According the court practice everywhere, including Albania, it would be difficult to determine with certainty a causal connection, if the diagnosis would be correct or therapy would be appropriate, injury or death would not come, or would be verified in a subsequent period, or would be less damage. Under these circumstances, it is impossible for the prosecution bodies to raise charges against doctors, because, any doubt concerning the charges shall be deemed to favor the accused person, the universal principle of criminal law, and provided in section 4 of Penal Procedure Code.

\subsection{Other countries experiences}

In The Criminal Code of Kosovo, in the chapter "Criminal Offences against public health", we encounter the offense "Unconscious Medical Treatment" provided in article 260. This offense is carried out by doctors or health workers as an illegal action and omission, or as an inappropriate method of treatment or failure to use appropriate hygienic measures and thereby caused the deterioration of the patient's health condition or his death. As we notice, in the designation of the offense, the lawmaker has used the term "treatment" in place of the term "medication" aiming to encompass all phases of medical treatment and avoid possible misunderstandings.

In France one of the key factors that explains a more extensive criminalization of medical negligence is the substantive offense which offers a wide range of possible criminal charges in the context of injury caused by negligence. The Criminal Code provides that there is délit 'in cases of recklessness, negligence, or failure to observe an obligation of due care or precaution imposed by any statute or regulation, where it is established that the offender has failed to show normal diligence, taking into consideration where appropriate the nature of his role or functions, of his capacities and powers and of the means then available to him. We should note the very broad extent of the criminalization of involuntary conduct in this definition, from simple negligence to recklessness (Kazarian, Griffiths and Brazier).

According to Italian experience, if a medical procedure is vitiated by a serious error in conduct, which causes injury to the patient, and there is a chain of causality between medical error and the damage suffered by the patient, the doctor may be held criminally liable for negligent personal injuries. Indeed, in Italian law, a crime for negligent personal injury is criminally liable to private prosecution by the person offended (in this case the patient). In the Italian penal code, the negligent injury is described as "an event that, even if it happened against the intention, occurred due to negligence, imprudence, unskillfulness or failure to comply with laws, regulations, orders and disciplines" (Traiana). 
In Greece, in case the wrongful act, omission or behavior that resulted to personal injury or death simultaneously constitutes a "criminal act" pursuant to the Greek Penal Code or other specific criminal laws, and criminal charges are brought against the responsible person, the injured person or the family of the deceased are entitled to intervene in the criminal proceedings as "civil claimants" in support of the criminal charge, and at the same time apply for the award of compensation from the Criminal Court (Pavlakis).

In England and Wales medical negligence usually only becomes a crime if negligence is gross, the patient dies and it caused or is a significant contributory factor to the death. There is no general crime of negligently causing injury. It does no matter how serious or even reckless the error is, the doctor will escape criminal liability if the patient survives, even if he is terribly disabled. For any prosecutor two major problems affect any charge of medical manslaughter, establishing that the error met the elusive concept of grossness and proving causation (Kazarian, Griffiths and Brazier).

Under Canadian law, adverse events may in principle be redressed through criminal, contract, and tort law remedies. However, the criminal law plays a very minor role in addressing medical malpractice, primarily because of the higher substantive and procedural standards required to impose criminal liability compared to civil liability. In addition to being infrequently used, the criminal law is poorly equipped to deal with medical misconduct because health professionals often work collaboratively, making it difficult to assign sole responsibility and blame (McDonald).

\section{Factors affecting consumption of the offense "careless medication" and possible preventive measures.}

There are a variety of factors, social, economic and cultural all of these combined with one another affect the consumption of criminal acts that damage human life and health in the field of medicine. A main cause of consumption of these offenses, especially the offense "careless medication" is negligence and carelessness of the medical staff.

Often doctors neglect their duties and do not take all appropriate measures when they face medical cases that put their professional skills in dilemma. Therefore, carelessness shown by medical personnel, in the form of negligence and excessive self-esteem affects the consequence of the offense and its risks.

Another cause is the incompetence of the medical staff, lack of professional qualifications and specialization or lack of specialized tools needed to exercise the appropriate medical activities. A great number of cases from the practice show that the authors of the offense" careless medication", perform medical acts for which they do not possess sufficient professional knowledge exceeding their competences on the role as medical staff. So, generally entities carrying out such offenses lack sufficient training to exercise the respective tasks.

Temperament and level of intelligence as an expression of the individual reaction (ie physician) to the harassment and external incitement, is another factor influencing the consumption of this offense. It may happen that a member of the medical staff under the pressure of strong emotions like fear and insecurity, would manifest changes of the mental status and activity, which may lead him to perform actions that may contain elements of the offense.

In the optics of a broader perspective, there are measurements that need to be taken to prevent this crime, like: improving the situation by increasing the welfare, reducing unemployment or informing all the social links about their rights and obligations by developing informational and cultural programs. Also improving the work conditions for medical staff, especially doctors, and endowing hospitals with sophisticated equipments for diagnosis and treatment of patients would significantly reduce the potential undesirable consequences. Enabling doctors and medical staff to have access in recent discoveries of medical science through qualifying programs will significantly increase their qualification level and would make possible the avoidance of many negative consequences coming from deficiency in knowledge and information.

\section{Conclusion}

"Careless medication" was the offence with the lowest number reporting in Albania, only few years ago. Generally the victims were withdrawn from denunciation. Causes for this situation could have been many, like, lack of information about the existence of the relevant provisions, the connections or social relations they had with the persons responsible of the offense, to maintain the case secret and not make it public, or simply because they would not believe that justice could be granted, etc. 
There has been an increase in denunciations of cases consuming the offense "Careless medication" compared with previous years. The law is still very faint and unclear in relation to this offence and this situation directly or indirectly creates psychological and professional pressure to medical staff.

It would be appropriate to make some changes in the Article 96 of the Criminal Code starting with the name "careless medication" to "careless treatment", since the term "medication" includes only the second stage of the patient's treatment, and then the interior of the article needs to clarify and concretize the range of possible indictments, based on the contemporary experience of international legislations.

\section{Bibliography}

[1] Coulter, James and Jo Ellins. Patient-focused interventions. A review of the evidence. The Health Foundation, 2006.

[2] European Economic and Social Committee. 15 November 2002. http://www.eesc.europa.eu/self-andcoregulation/documents/codes/private/085-private-act.pdf.

[3] Kazarian, Melinee, Danielle Griffiths and Margaret Brazier. Academia.edu. 2011. http://www.academia.edu/1520085/Criminal_Responsability_for_Medical_Malpractice_in_France.

[4] Lole, Arqile. "Mjekimi I pakujdesshem." Revista Drejtesia Popullore (1979).

[5] McDonald, Fiona. "The Criminalisation of Medical Mistakes in Canada: A Review." Health Law Journal (2008): p 4-5.

[6] Meksi, Sokrat. "Disa çështje lidhu rme krimin e mjekimit të pakujdesshëm." Revista Drejtësia Popullore 2 (1980): p 68.

[7] Miles, Steven H. The Hippocratic Oath and the Ethics of Medicine . New York: Oxford University Press, 2004.

[8] P.Pavli. "Pergjegjesia Penale e Mjekut dhe e Punonjesve te tjere te Mjekesise." Revista Drejtesia Popullore 3 (1971).

[9] Pavlakis, loannis M. Greek Law Digest. 2012. http://www.greeklawdigest.gr/topics/basic-aspects-of-civil-law.

[10] Pikoulis, Emmanouil, et al. "Medical progress, Evolution of medical education in ancient Greece." Chinese Medical Journal ; (2008): p 2202.

[11] Shehata, Mustafa. "The Father of Medicine: A Historical Reconsideration." Journal Medicin Ethics 12 (2004): p 171-176.

[12] Traiana, Francesco. "Medical malpractice: The experience in Italy." Clinical Orthopaedics and Related Research 467 (2008): $p 437$. 